Title:

ESTIMATION OF DAMAGE PREFERENCE FROM STRIKE PARAMETERS

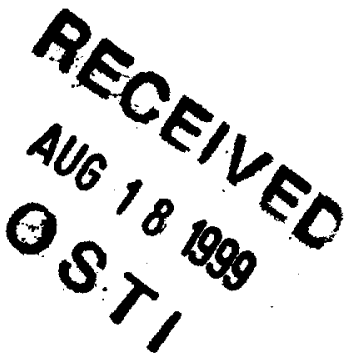

Submitted to:

For discussions outside the Laboratory

Date: 11 September 1998

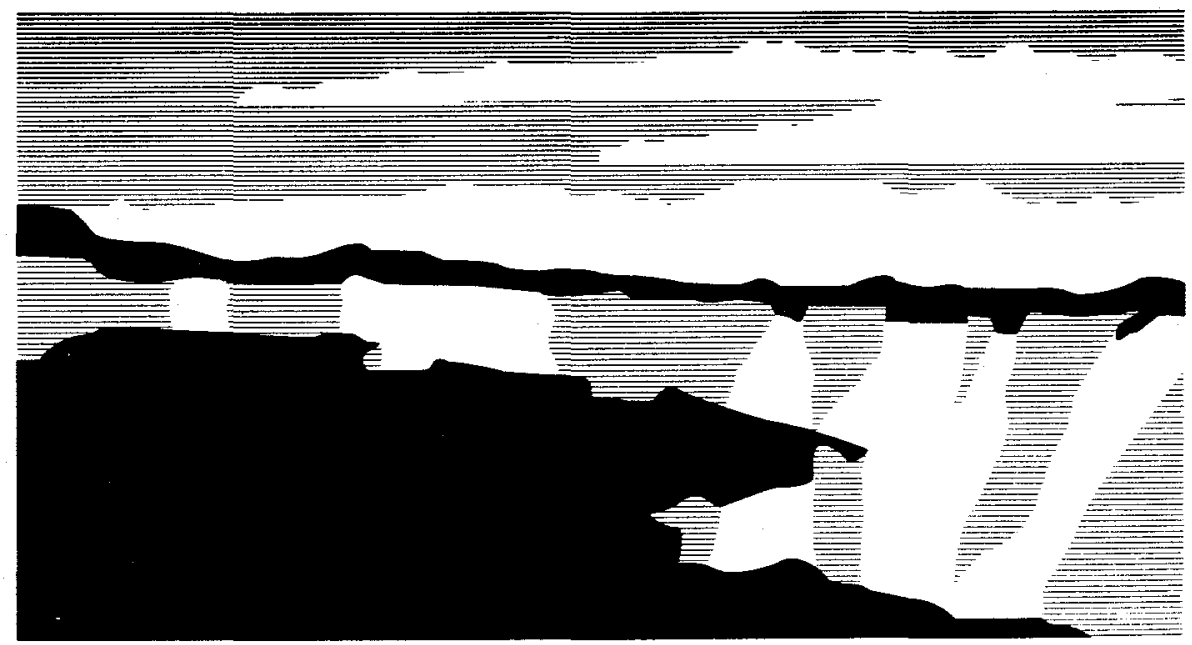

Los Alamos National Laboratory, an affirmative action/equal opportunity employer, is operated by the University of California for the U.S. Department of Energy under contract W-7405-ENG-36. By acceptance of this article, the publisher recognizes that the U.S. Government retains a nonexciusive, royalty-free license to publish or reproduce the published form of this contribution, or to allow others to do so, for U.S. Government purposes. The Los Alamos National Laboratory requests that the publisher identify this article as work performed under the auspices of the U.S. Department of Energy. 


\section{DISCLAIMER}

This report was prepared as an account of work sponsored by an agency of the United States Government. Neither the United States Government nor any agency thereof, nor any of their employees, make any warranty, express or implied, or assumes any legal liability or responsibility for the accuracy, completeness, or usefulness of any information, apparatus, product, or process disclosed, or represents that its use would not infringe privately owned rights. Reference herein to any specific commercial product, process, or service by trade name, trademark, manufacturer, or otherwise does not necessarily constitute or imply its endorsement, recommendation, or favoring by the United States Government or any agency thereof. The views and opinions of authors expressed herein do not necessarily state or reflect those of the United States Government or any agency thereof. 


\section{DISCLAIMER}

Portions of this document may be illegible in electronic image products. Images are produced from the best available original document. 


\title{
ESTIMATION OF DAMAGE PREFERENCE FROM STRIKE PARAMETERS
}

\author{
Gregory H. Canavan
}

Estimation of an opponent's damage preference is illustrated by discussing the sensitivity of stability indices and strike parameters to it and inverting the results to study the sensitivity of estimates to uncertainties in strikes. Costs and stability indices do not generally have the monotonicity and sensitivity needed to support accurate estimation. First and second strikes do. Second strikes also have proportionality, although they are not unambiguously interpretable. First strikes are observable and have the greatest overall power for estimation, whether linear or numerical solutions are used.

An essential element of the analysis of crisis stability is that of the estimation of an opponent's resolve from his behavior in successive stages of and engagement. The process is illustrated here by discussing the sensitivity of the stability index and first strike costs at moderate force levels on the parameter $L$ that measures one's relative preference for inflicting damage on one's opponent and for preventing it on oneself. That process is then inverted to show the difficulty of estimating $L$ from indices and costs, even if they are observable. Costs and stability indices do not generally have the monotonicity and sensitivity to $L$ needed to support accurate estimation L. First and second strikes do have monotonicity and sensitivity. Second strikes also have proportionality, although they are not unambiguously interpretable, as they reflect decisions by both sides. Thus, first strikes have the greatest overall power for estimation, whether linear or numerical solutions are used for the inversion.

Analysis of symmetric exchanges can be done in terms of the first and second strikes

$$
\begin{aligned}
& \mathrm{F}=(1-\mathrm{f}) \mathrm{mM}, \\
& \mathrm{S}=\mathrm{QmM} .
\end{aligned}
$$

where survivable forces are ignored for simplicity, $f$ is the fraction of the attack allocate to missiles, $Q \approx q^{r}$ is the average survival probability of vulnerable missiles, $r=f m$, and $p=1-q$ is the single shot probability of kill. At low force levels the first and second strikes reduce to ${ }^{1}$

$$
\begin{aligned}
& (1+\mathrm{L}) \mathrm{C}_{1} \approx \mathrm{kS}+\mathrm{L}(1-\mathrm{kF})=\mathrm{kQmM}+\mathrm{L}[1-\mathrm{k}(\mathrm{m}-\mathrm{r}) \mathrm{M}], \\
& (1+\mathrm{L}) \mathrm{C}_{2} \approx \mathrm{kF}+\mathrm{L}(1-\mathrm{kS})=\mathrm{k}[\mathrm{W}-\mathrm{rM}]+\mathrm{L}[1-\mathrm{k}[\mathrm{QmM}+\mathrm{nN}] .
\end{aligned}
$$

where it is assumed that each side has $1 / \mathrm{k} \sim 1,000$ value targets. The cost of damage to self and incomplete damage to other are weighted with a parameter $L$, which measures the attacker's relative preference for damage to the other and prevention of damage to self. ${ }^{2}$ For modest forces, the ratio of costs, which is a rough stability index, reduces to

$$
\mathrm{I}=\mathrm{C}_{1} / \mathrm{C}_{2} \approx 1+\left(\mathrm{C}_{1}-\mathrm{C}_{2}\right)(1+\mathrm{L}) / \mathrm{L}=1+(1+\mathrm{L}) / \mathrm{L} \mathrm{k}(\mathrm{S}-\mathrm{F}),
$$


The attacker minimizes the cost of striking first by minimizing $C_{1}$ in Eq. $(3),{ }^{3}$ which produces

$$
\mathrm{r}=\ln (-\mathrm{L} / \mathrm{mlnq}) / \mathrm{lnq} \text {, }
$$

which is shown in Fig. 1. For $m=1$ and $L$ small, $r=m$. For $L>0.3, r$ falls roughly as $\sim 1 / L$. for larger $\mathrm{m}, \mathrm{r}$ increases less than proportionally at each $\mathrm{L}$. Substituting produces

$$
\mathrm{Q} \approx-\mathrm{L} / \mathrm{mlnq} \text {, }
$$

shown in Fig. 2, which is linear in $\mathrm{L}$ and $\sim 1 / \mathrm{m}$. The normalized first strike $F / M=\mathrm{m}-\mathrm{fm}=\mathrm{m}-\mathrm{r}$ is shown in Fig. 3. The first strike on value is large for large $\mathrm{L}-$ particularly for large $\mathrm{m}$-and decreases with $\mathrm{L}$, reaching zero at $\mathrm{L} \approx 0.3$ for $\mathrm{m}=1$ and about unity at $\mathrm{L}=0.2$ for $\mathrm{m}=3$. The normalized second strike $\mathrm{s}=\mathrm{S} / \mathrm{M}=\mathrm{mQ}=-\mathrm{L} / \mathrm{lnq}$ is linear in $\mathrm{L}$ and independent of $\mathrm{m}$. Figure 5 shows the stability index $\mathrm{I}$, which varies little for $\mathrm{L}<0.4$, varies $<15 \%$ overall for $\mathrm{m}=2$, and falls monotonically with $\mathrm{L}$ in this approximation for $\mathrm{m}=3$, as discussed further below. Figure 6 shows the normalized first strike $\operatorname{cost} \mathrm{C}_{1} / \mathrm{kM}$, which increases monotonically with $\mathrm{L}$, particularly for $\mathrm{m}=1$.

Estimation of damage preference $L$. The results of the previous section can be inverted to show the sensitivity of estimates of $L$ to those in the observed quantity. The normalized first strike cost of Fig. 6, $\mathrm{C}_{1} / \mathrm{kM}$, would be a useful indicator, as it increases strongly and monotonically with L. However, that cost is known only to the possible attacker. He does not need to estimate it, and nothing observable by the second striker will help him determine it directly. Similarly, the stability index of Fig. 5 is observable only indirectly through the frequency of crises, and even then the observation would only be useful for large $\mathrm{m}$, as I does not vary strongly or monotonically for values of $L$ large enough to be of concern.

The second strike of Fig. 4 is particularly useful if the engagement occurs in stages, as it is monotonic, linear in $\mathrm{m}$, and observable. Even if the normalized strike was only known to lie within 0.25 to 0.4 , that would indicate that $L$ lay between $\approx 0.6$ and 0.6 , i.e., certainly in a stable region. Second strikes of $s \approx 0.2$ would generate non-aggressive values of $L$ an order of magnitude smaller than the aggressive values $\gg 1$ estimated from second strikes $\approx 1$.

Figure 3 shows that similar discrimination is possible for first strikes, although they saturate for large $\mathrm{L}$ and more weapons are shifted to value. However, the discrimination is adequate for values of $L$ from 0.2 to $\sim 1$. For example, a normalized first strike $=1$ with missiles with $\mathrm{m}=2$ would imply $\mathrm{L}=0.6$. A $10 \%$ uncertainty in the first strike would give a range of $\mathrm{L}$ from 0.55 to 0.8 , which is wide, but still useful. For smaller strikes, the range is smaller. The survival probability $\mathrm{Q}$ is not independently observable, and the allocation $r=\mathrm{fm}$ of Fig. 1 is linearly dependent on the first strike through Eq. (1).

Numerical solution. The calculations above are done with parameters that exceed the bounds of the approximations used in deriving Eqs. (1)-(7) in order to show the above scalings in their simplest light. The results of numerical solutions for the full nonlinear equations are 
presented here and compared with those of the linearized equations. Figure 7 shows the linearized and numerical $f$ vs $L$ for $m=3$. The results from the numerical solutions are slightly greater than those from the analytic optimization. the difference is $\approx 10 \%$ for small $\mathrm{m}$, growing to $25 \%$ at $\mathrm{L}=1.8$. Figure 8 shows the first and second strikes, which are similar to the linearized normalized strikes of Figs. 3 and 4. Figure 9 shows the first and second strike costs and their ratio, which is the index $I$. While the first strike cost still falls as in Fig. 6 , the second strike cost falls less rapidly, so the index only falls to $\approx 0.5$, although it still falls monotonically with $\mathrm{L}$. However, as noted above, this dependence is not directly observable.

The principal observables are the first and second strikes in a sequence of exchanges. As noted above, the latter is directly proportional to $\mathrm{L}$, the former is strongly dependent on it. The dependence of $\mathrm{F}$ on $\mathrm{L}$ is quite close to that from the linearized optimization; thus, the sensitivities discussed above still obtain for the numerical solutions. This is a significant result in that the size of the first strike, which is potentially the strongest indicator or the opponent's damage preference, is also quite sensitive to that preference in the range of 0.2-1 of concern.

Summary and conclusions. The estimation of an opponent's resolve from his behavior in engagements is an essential element of crisis stability analysis. It is illustrated here by the sensitivity of strike parameters, stability indices, and first strike costs at moderate force levels to the parameter $L$ that measures one's relative preference for inflicting damage and preventing damage to self. Inversion of that process shows the difficulty of estimating $\mathrm{L}$ from indices and costs, even if they are observable. Costs and stability indices do not generally have the monotonicity and sensitivity to $\mathrm{L}$ needed to support accurate estimation of $\mathrm{L}$. First and second strikes do have monotonicity and sensitivity. Second strikes also have linear proportionality, although they are not unambiguously interpretable, reflecting decisions by both sides. Thus, first strikes have the greatest overall power for estimation, whether the linear or numerical solutions are used for the inversion.

\section{References}

1. Canavan, "Stability at Low Symmetric Force Levels," Los Alamos National Laboratory Report LA-UR-97-3728, September 1997.

2. G. Kent and R. DeValk, "Strategic Defenses and the Transition to Assured Survival," RAND Report R-3369-AF, October, 1986.

3. A. Piontkovsky, "New Paradigm of Strategic Stability," A. Zichichi ed, International Seminar on Nuclear War and Planetary Emergencies (London, World Scientific, 1993) 


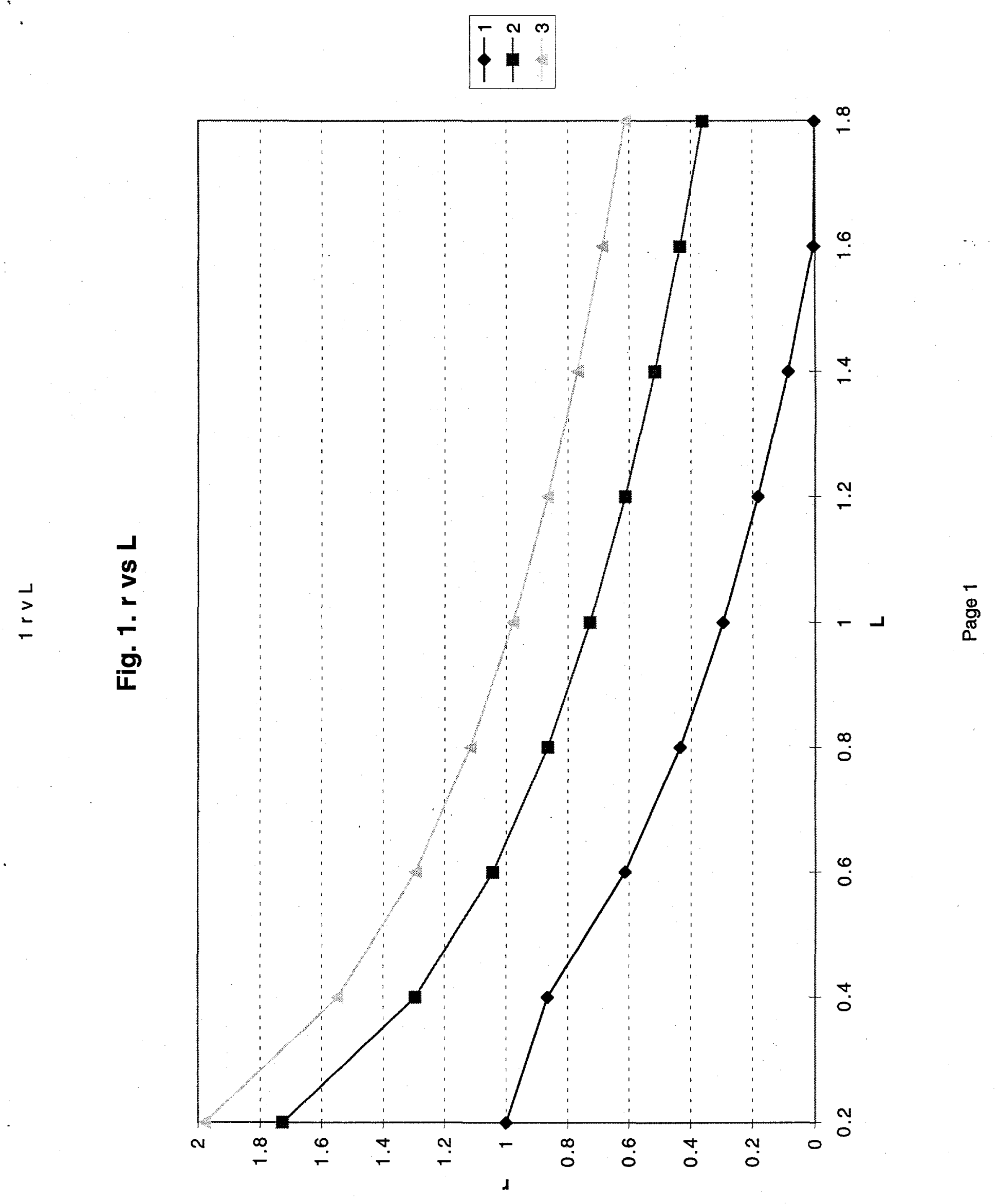


Fig. 2. $Q$ vs $L$

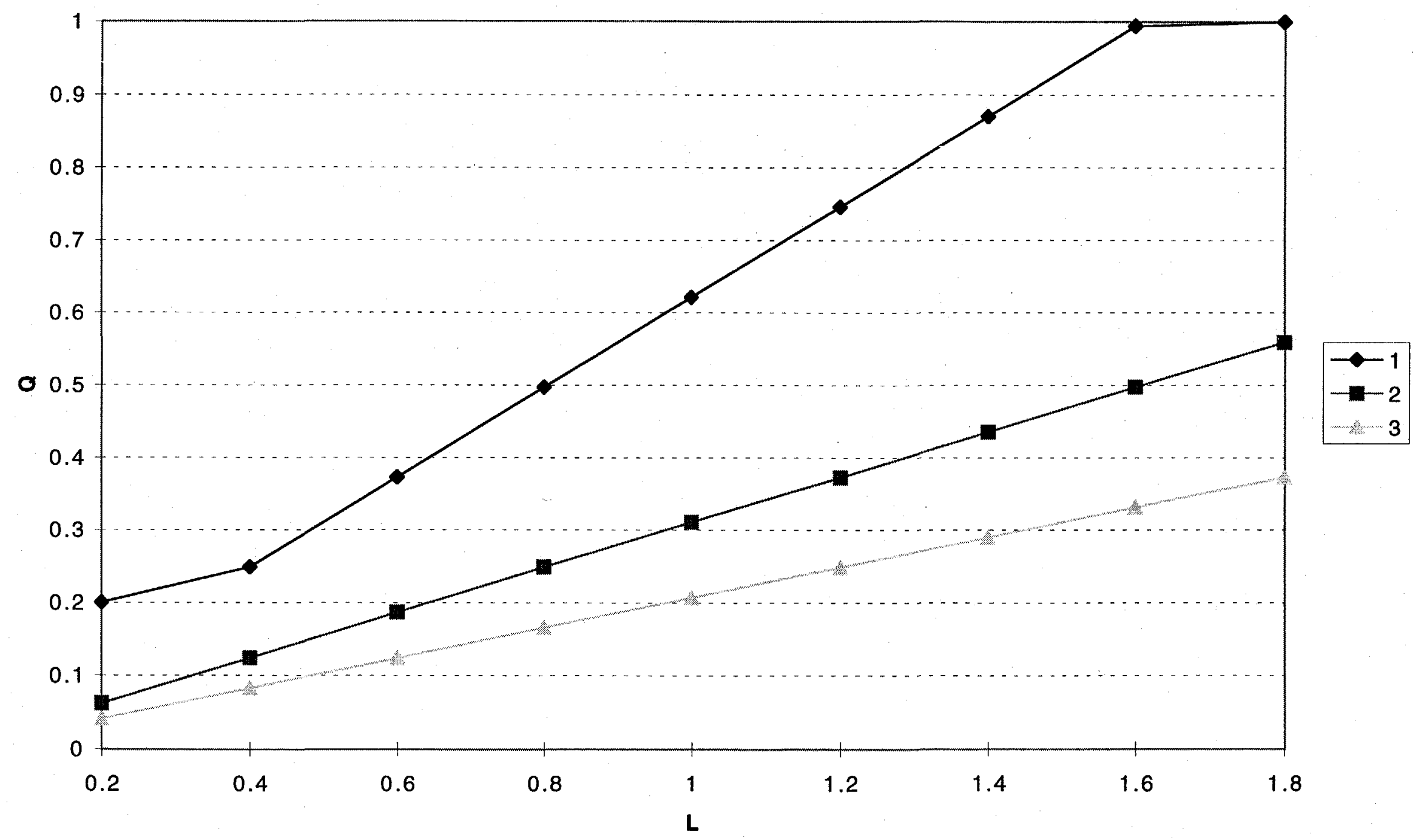




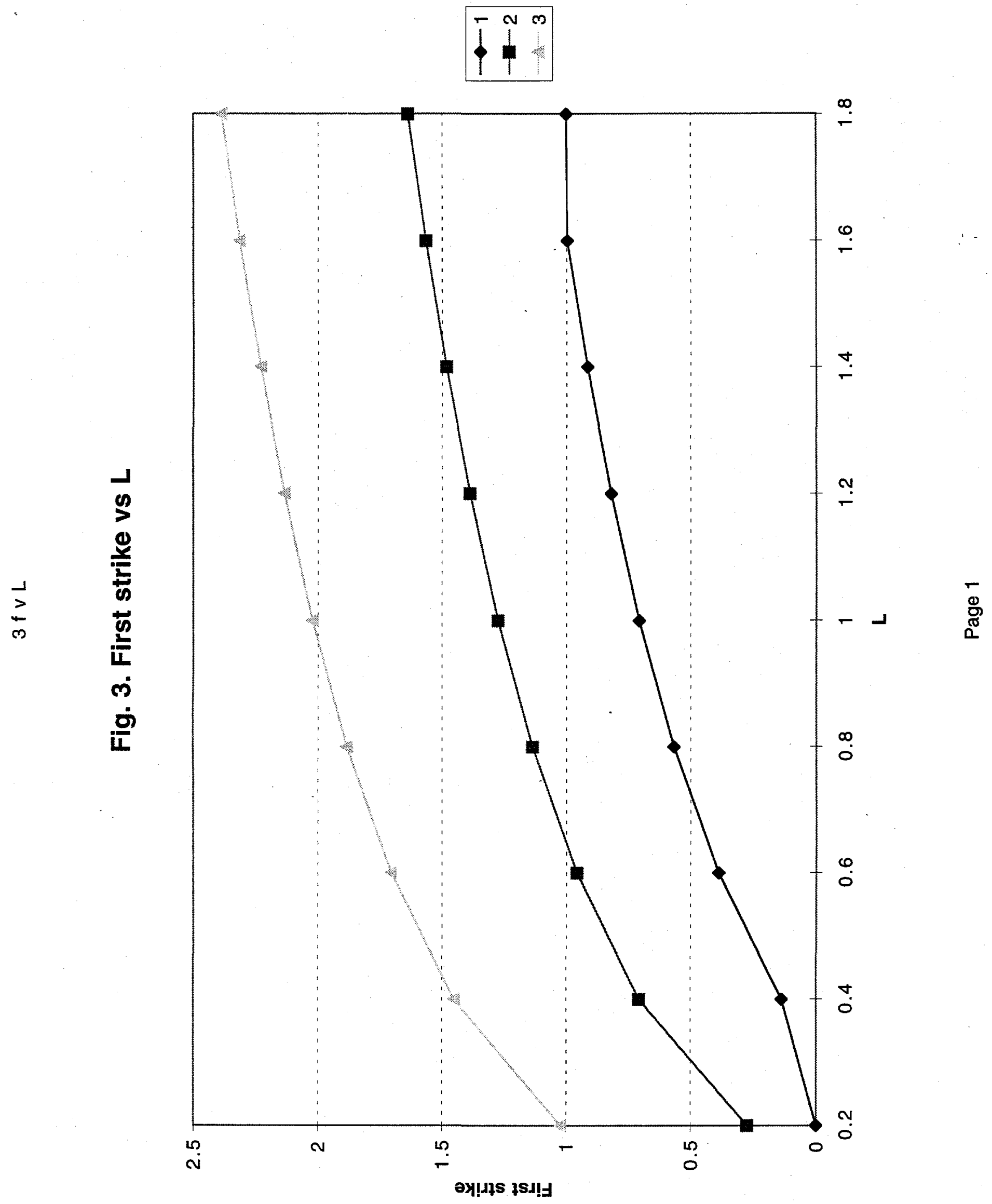


Fig. 4. Second strike vs L

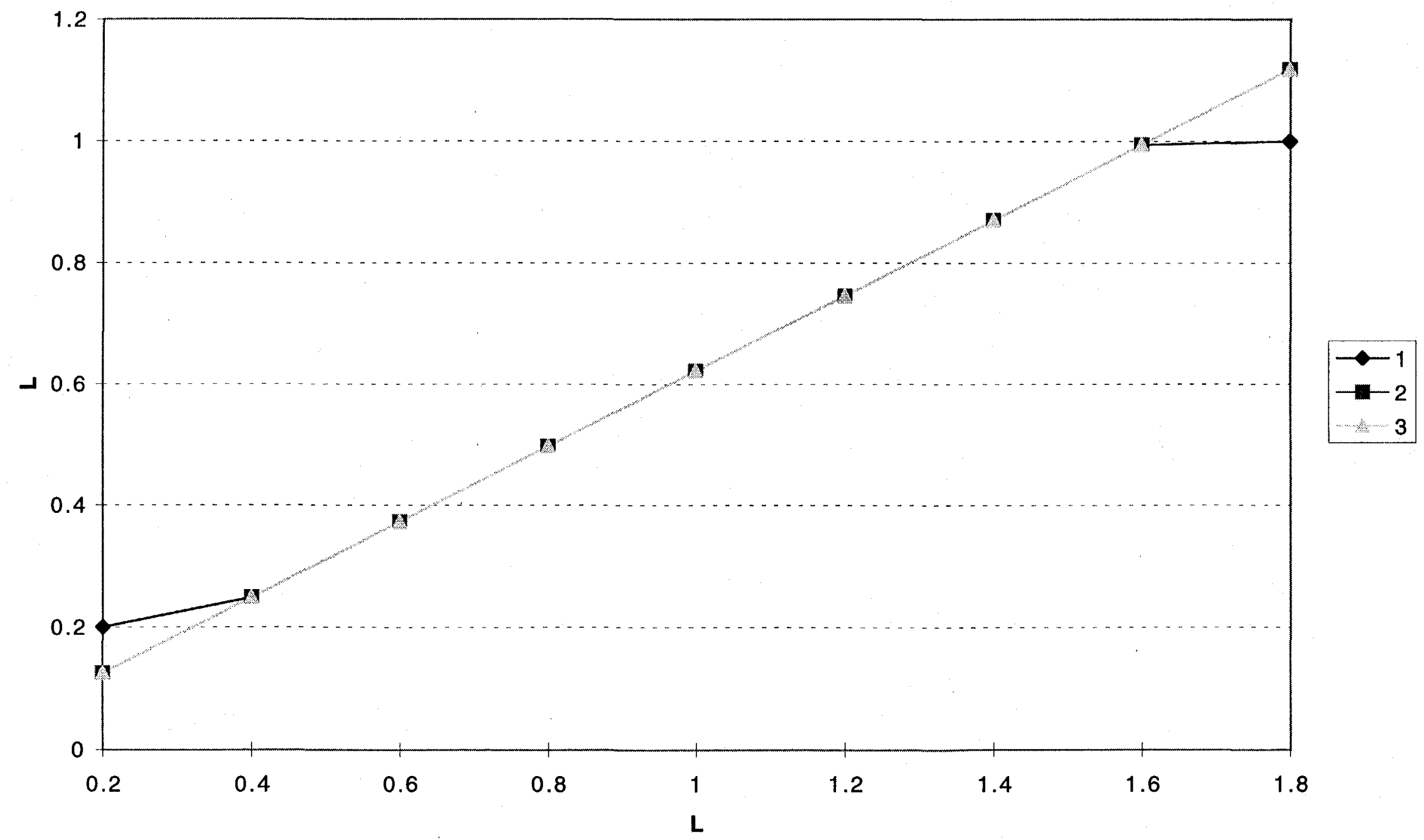

Page 1 
5 I V L

Fig. 5. I v L

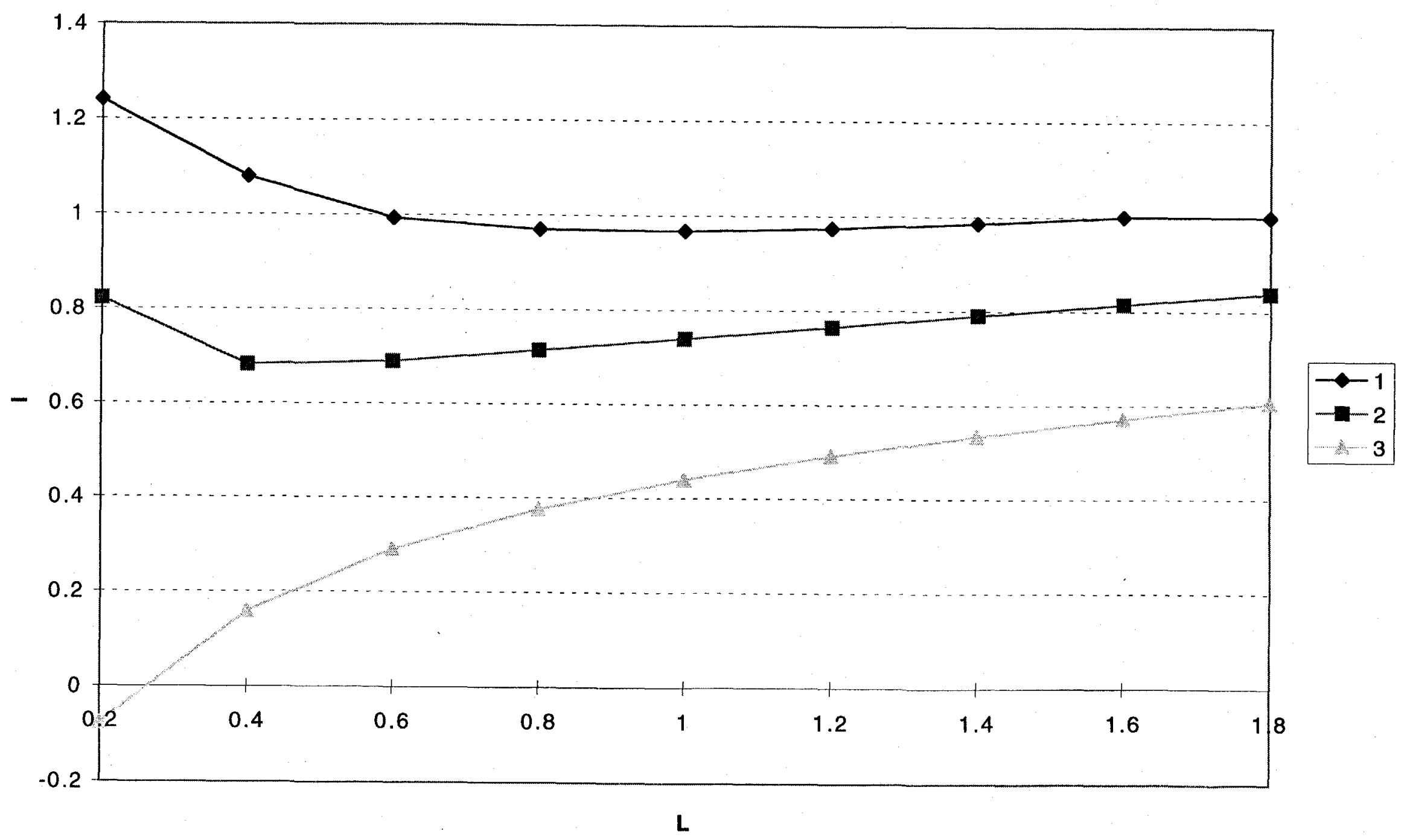

Page 1 
$6 \mathrm{c} \mathrm{v} \mathrm{L}$

Fig. 6. c v L

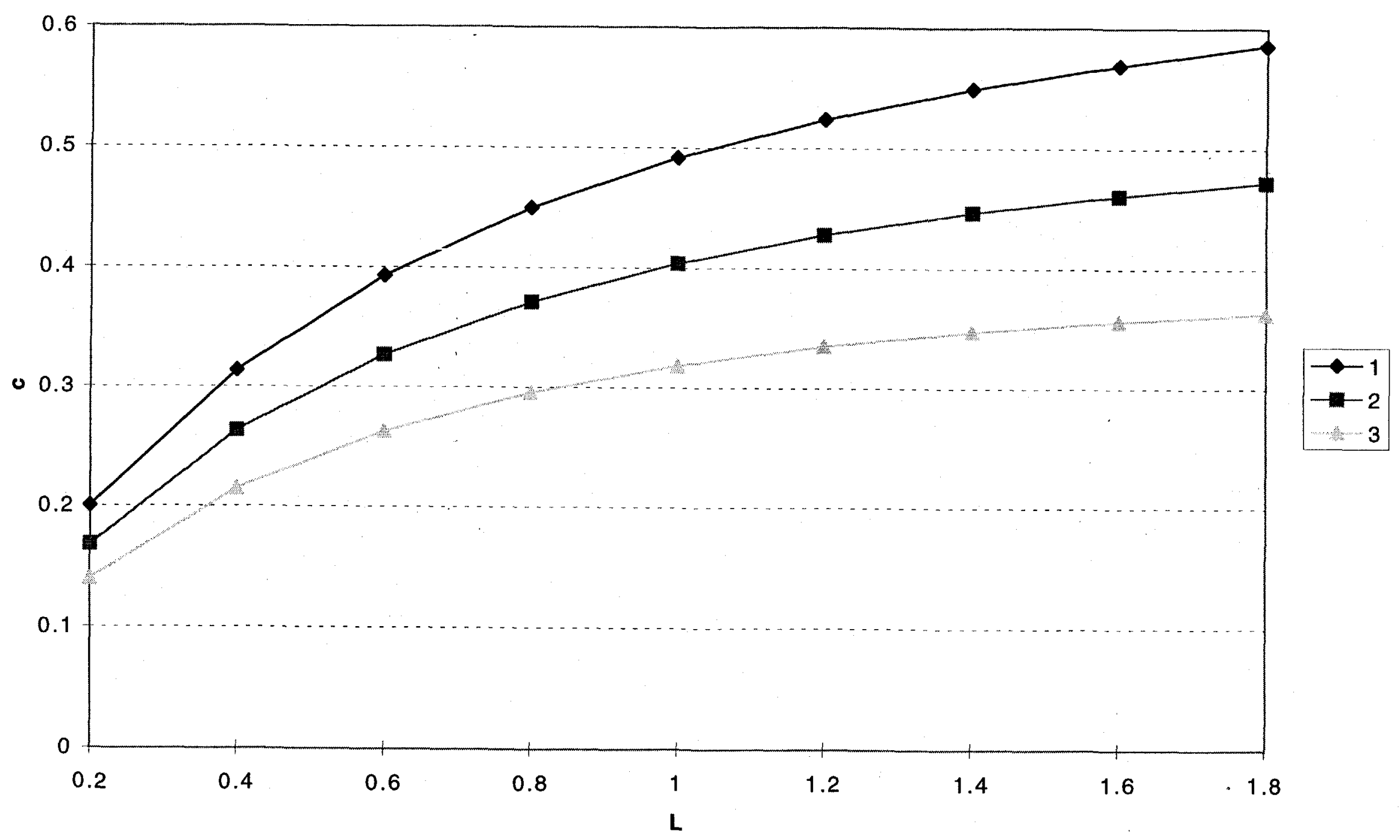

Page 1 
f\&fnum $\vee L$

Fig. 7. Allocations $f \&$ fnum vs $L$

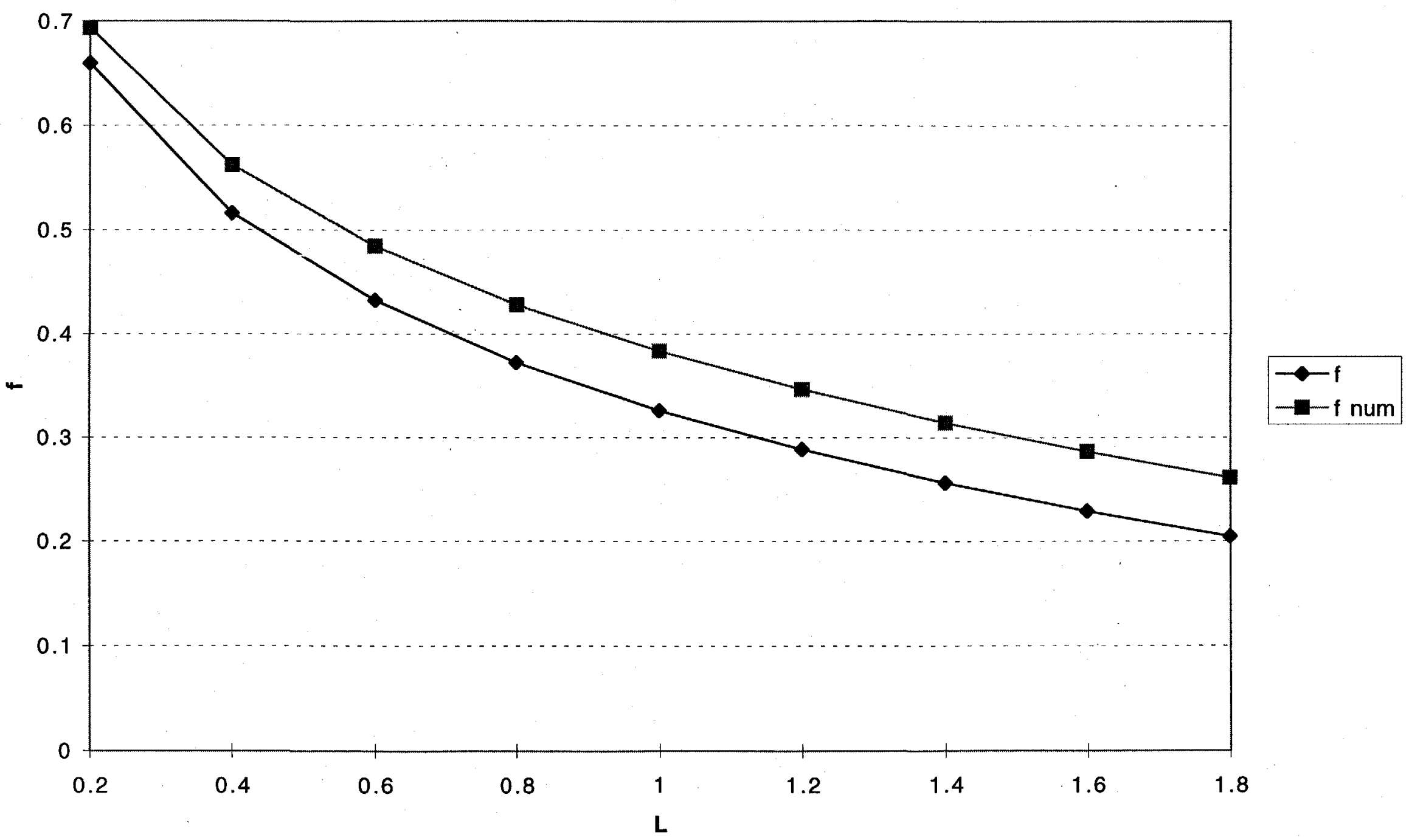


$8 F \& S$

Fig. 8. F \& S strikes vs $L$

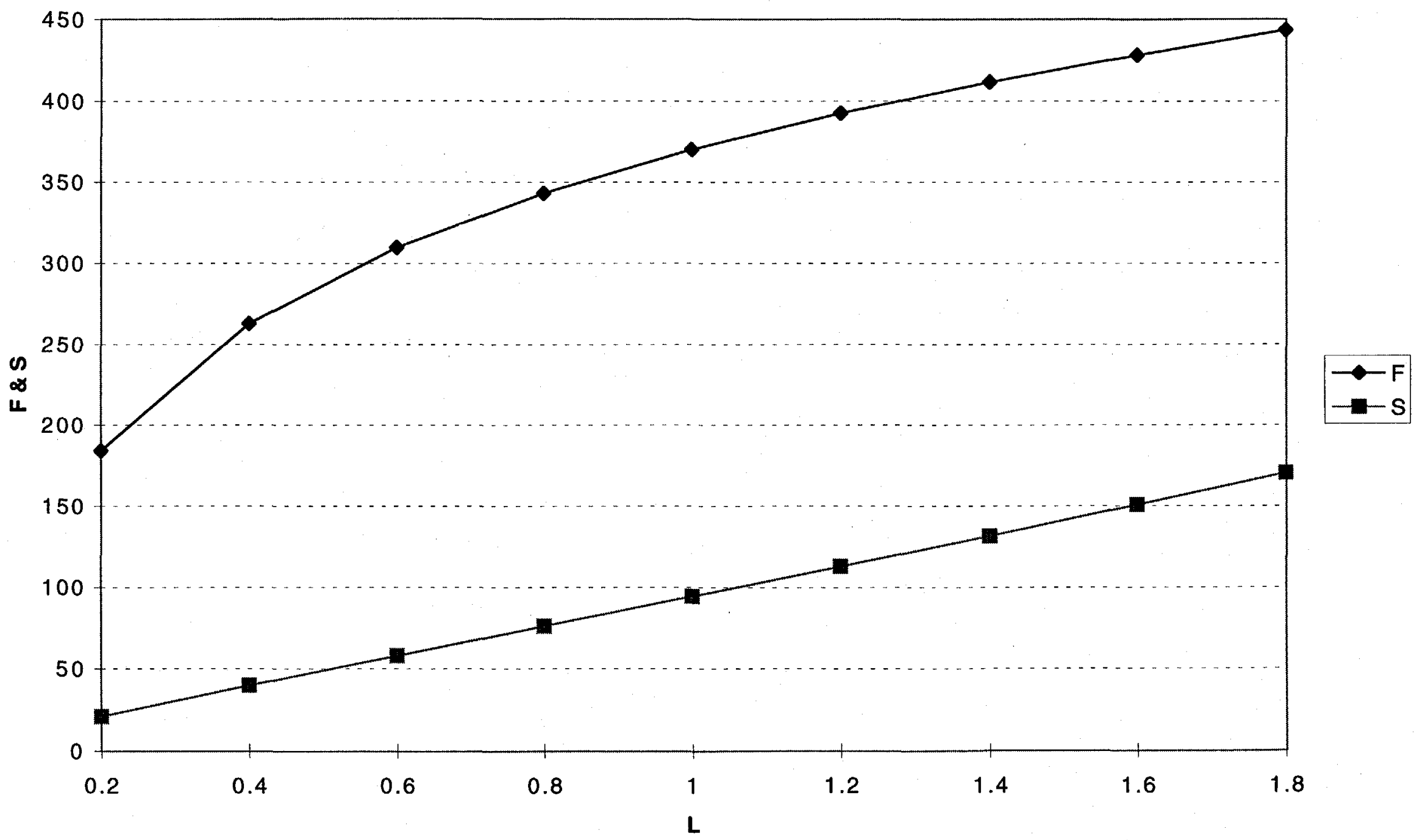

Page 1 
$9 \mathrm{C} \& I \vee L$

Fig. 9. C and Index vs L

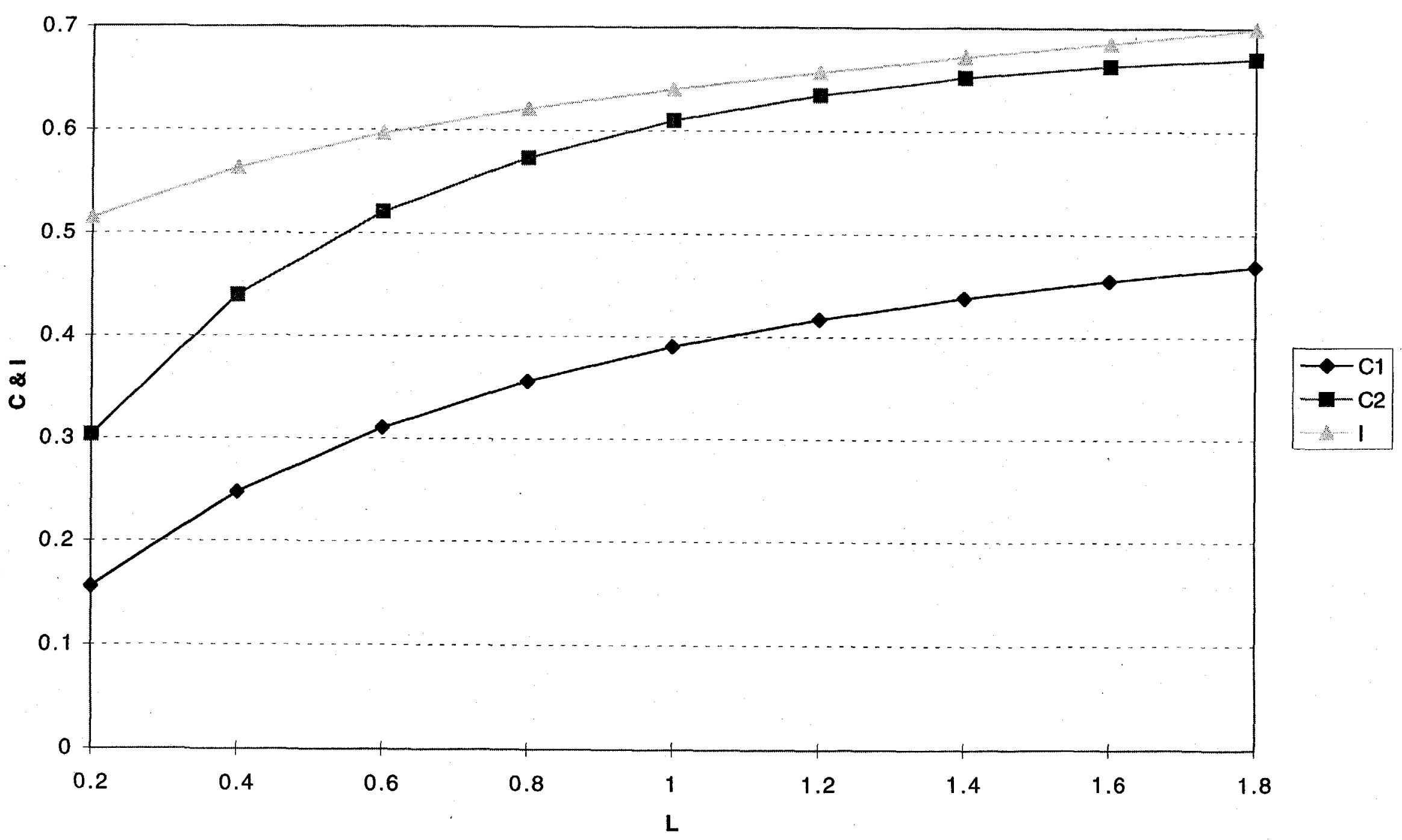

Page 1 